American Journal of Applied Sciences 9 (4): 472-477, 2012

ISSN 1546-9239

(C) 2012 Science Publications

\title{
Tourism Equilibrium Price Trends
}

\author{
${ }^{1}$ Mohammad Mohebi and ${ }^{2}$ Khalid Abdul Rahim \\ ${ }^{1}$ Department of Business Management, Faculty of Management, \\ Hormozgan University, Bandarabbas, Iran \\ ${ }^{2}$ Institute of Agricultural and Food Policy Studies, Kualalumpore, Malaysia
}

\begin{abstract}
Problem statement: A review of the tourism history shows that tourism as an industry was virtually unknown in Malaysia until the late 1960s. Since then, it has developed and grown into a major industry, making an important contribution to the country's economy. By allocating substantial funds to the promotion of tourism and the provision of the necessary infrastructure, the government has played an important role in the impressive progress of the Malaysian tourism industry. One of the important factors which can attract tourists to Malaysia is the tourism price. Has the price of tourism decreased? To answer this question, it is necessary to obtain the equilibrium prices as well as the yearly trend for Malaysia during the sample period as it will be useful for analysis of the infrastructure situation of the tourism industry in this country. The purpose of the study is to identify equilibrium tourism price trends in Malaysian tourism market. Approach: We use hotel room as representative of tourism market. Quarterly data from 1995-2009 are used and a dynamic model of simultaneous equation is employed. Results: Based on the result during the period of 1995 until 2000, the growth rate of the equilibrium price was greater than consumer price index and producer price index. Conclusion: In the Malaysian tourism market, new infrastructure during this period had not been developed to keep pace with tourist arrivals.
\end{abstract}

Key words: Tourism demand and supply, tourism price, country's economy, equations model, tourism history, malaysian tourism, equilibrium prices, tourism supply, infrastructure situation, tourism expenditure, log linear

\section{INTRODUCTION}

A review of the tourism history shows that tourism as an industry was virtually unknown in Malaysia until the late 1960s. Since then, it has developed and grown into a major industry, making an important contribution to the country's economy. By allocating substantial funds to the promotion of tourism and the provision of the necessary infrastructure, the government has played an important role in the impressive progress of the Malaysian tourism industry. The Malaysian government has expanded the tourism industry and set several development targets after 1970, for instance, creating more employment opportunities, increasing foreign exchange earnings and income levels, nurturing local development, strengthening and spreading the economic foundation and improving government revenue. From the 1980s, one of the major policies of the government in the tourism sector has been to encourage private sector tourism development. For the development of accommodation, visitor centre facilities, manpower development and encouraging the participation of local Malays in the tourism industry, more incentives were given to the private sector. Since 1987, tourism has been one of the major economic focuses in Malaysia and the Government has been resolute in expanding the tourism industry in the country. From the 1997-2008, the hotel industry in Malaysia saw an acceptable 38\% growth. The number of hotel rooms in 1998 was about 98,000 and increased to 160,000 in 2008 . The industry employs more than 830,000 workers or $7.7 \%$ of the total Malaysian workforce. Hotel occupancy rates in Malaysia during the 1995-2008 fluctuated within a reasonable and acceptable range. For example, the average hotel occupancy rate in 2000 was $57.2 \%$, continued to increase to $58.6 \%$ in 2001 and $60.86 \%$ in 2002 before dipping to $56.01 \%$ in 2003 and then bouncing back to $66.10 \%$ in 2004 . There was a marginal increase the following year to $67.71 \%$ before dipping almost 10 $57.78 \%$ in 2006. In 2007, the average room occupancy rate shot up more than 11-69\%, before sliding downward again in 2008-66.3\%. One of the important factors which can attract tourists to Malaysia is the

Corresponding Author: Mohammad Mohebi, Department of Business Management, Faculty of Management,

Hormozgan University, Bandarabbas, Iran 
tourism price. Has the price of tourism decreased? To answer this question, it is necessary to obtain the equilibrium prices as well as the yearly trend for Malaysia during the sample period as it will be useful for analysis of the infrastructure situation of the tourism industry in this country.

Tourism market model: In every market economy, the price system should function in a way that the amount of products producers are desirous to supply equals the amount consumers are desirous to demand for, i.e., scheduled supply and demand must be balanced. Theoretically, when prices are too high for such balance to take place, suppliers will not be capable to clear all they produce via markets. In such a case, price and quantity supplied must be lowered. On the contrary, when prices are too low, there is additional demand and buyers will increase prices with more supply. Ceteris paribus, for every product in an economy there is a single equilibrium market price and amount, standing for a partial balance in the aggregate economy.

Tourism demand and supply model: According to Crouch (1994), there are different sets of factors for explaining and stipulation of the demand model. Using these factors based on the terms and period studied are varied. One of the commonly-used variables as a dependent variable is the number of nights spent at a tourist accommodation. In this study, we use the number of hotel rooms rented as a proxy of the Malaysian tourism model. Basically, the selected model for tourism demand is restricted by several econometric limitations and problems. Selecting suite explanatory variables in the model is restricted to degree of freedom and availability of data. Multicollinearity, endogeneity, omitted variable problems and others Mohebi et al. (2011). Also, simultaneous equations model includes four factors. Real personal income per capita of destination countries, exchange rate, lagged of total rooms sold and finally, Malaysian average daily hotel room price, will be used as explanatory variables. Due to some problems (as mentioned above), we use the principle determinants of tourism demand and the model does not include all influence variables.

From the host country's standpoint, supply conditions are major factors in attracting more tourism inflows to the destination. There is a problem in tourism supply measurement because there are no precise and determined criteria of tourism supply. Therefore, we can not exactly say that the mean of tourism supply is services related to tourism or goods supply as tourism. Hence, we have to ignore studies relating to tourism supply or place minimum emphasis on it. Nearly all researchers use supply of hotel rooms as tourism supply in their researches. It seems that the hotel room is the best selection on hand as used by Zhou et al. (2007). In this study, we focus on one group of commodities called pure tourism but we are limited to selecting only one section of pure tourism as accommodation. Based on the statistics the share of accommodation in tourism expenditure is more than $32 \%$ of total tourism expenditure in Malaysia. We choose hotel accommodation as a proxy for the tourism industry because lodging services are the biggest single product group in total tourist expenditure. The relationship between tourism and social, economic and environmental factors is very complex. Therefore, modelling tourism supply is difficult due to lack of product definition and clear combination of external factors in the production of the tourism function. According to the tourism literature, in many empirical tourism studies to model tourism supply, an inverted tourism supply curve is estimated. In this approach, the supply price of hotel rooms is assumed as a mark-up over marginal cost. This approach has been used by (Fujii and Mak, 1980; Bonham and Gangnes, 1996; Zhou et al., 2007). In our model, for price variable, we use the Malaysian average daily hotel room rate as used (Zhou et al., 2007; Mohebi et al., 2011). Also, we use the total rooms rented (or rooms sold) as a proxy of the number of visitors and total rooms available as supply of tourism. For production cost, we use the Malaysian producer price index. Also, room occupancy rate will be used as an explanatory variable. Also, to capture the short run effect we include lag of endogenous variable to the model. In order for the estimated coefficients to be construed as elastic, the tourism supply and demand functions are estimated in log linear form too. The sets of equations with supply and demand in log linear form are given below:

$$
\begin{aligned}
& \ln \mathrm{ARR}=\alpha_{20+} \alpha_{21} \ln \mathrm{QRD}+\alpha_{22} \ln \mathrm{OCP}+ \\
& \alpha_{23} \ln \mathrm{PPM}+\ln \mathrm{ARR}(-1)+\mathrm{e}_{2} \\
& \ln \mathrm{QRD}=\alpha_{10}+\alpha_{11} \ln \mathrm{Y}+\alpha_{12} \ln \mathrm{EX}+ \\
& \alpha_{13} \ln \mathrm{ARR}+\ln \mathrm{QRD}(-1)+\mathrm{e}_{1}
\end{aligned}
$$

where, QRD is total room sold in Malaysia, Y real personal income per capita generation countries, EX is exchange rate, ARR is Malaysian average daily hotel room rate and -e- is error term, OCP is the room occupancy rate, defined as the ratio of quantity demand of rooms to room supply or room, capacity as it used before Qu et al. (2002) in Hong Kong tourism model, PPM producer price index, QRD is total room rented (or room sold) and -e- is error term. In order for the 
estimate coefficients to be construed as elasticity's, the tourism supply and demand functions are estimated in $\log$ linear form too. Basically, Eq. 1 and 2 are in structural form. As mentioned, we cannot estimate these equations by ordinary least squares. Therefore we will use a simultaneous equations model.

\section{MATERIALS AND METHODS}

We used a linear-log specification of the supply and demand model (Eq. 1-2), which is estimated by using the Weighted Two-Stage Least-Squares Estimator (W2SLS). Both demand and supply equations are overidentifying. This is because in our model, K-k is more than M-1 and thus the equation is over identified. All exogenous variables of the system are used as instruments for the endogenous variables. The parameter estimation of the model is shown in Table 1. In the system equation model, the $\mathrm{R}^{2}$ is not a good criterion because the $R^{2}$ changes between $-\infty$ and 1 . Therefore, generally in such a system equation it is better to use another criterion to adjust the $\mathrm{R}^{2}$ that was proposed. Based on the Carter-Negar approach in the estimated demand equation, the explanatory variables collectively explain the approximate $99 \%$ of the variation in the dependent variable $\left(R^{2} s=0.99\right)$. In this study, we had to use the AR term in the model to solve the problem of residual terms for both equations, but the primary estimation showed that without the application of AR in our model, the chosen explanatory explains less than $70 \%\left(\mathrm{R}^{2}\right)$ of the total variation in the demand and supply equation.

\section{RESULTS}

Since we estimated the model with a double logarithmic form, therefore the coefficients of variables in double log liner model indicate the elasticity of demand and supply with respect to the independent variables (Anastassiou and Dritsaki, 2005; Arbel and Ravid, 1983; Bird, 1992; Seifolddini-Faranak et al., 2009; Smith, 1988). Elasticity measures the percentage change in the quantity of the dependent variable (quantity) with one percent change in the explanatory variables (price and income). Elasticity estimation of the results is reported in Table 1.

The regression coefficients can be interpreted as follows: the coefficient of price in demand equation measures the absolute change in total rooms sold (quantity of demand) following a unit proportional change in price with everything else constant. In the demand equation, the coefficient of price variable (average hotel room rate) is -0.22 . This result clearly shows that tourists demand is price-inelastic in the short run but it is sensitive to price. Hence, a $1 \%$ increase in tourism price in Malaysia would reduce, by more than $0.2 \%$, the demand of tourism. The long-term elasticity is the short-term elasticity divided by one minus the coefficient on lagged dependent variable. We apply this method to calculate the long run elasticity of supply and demand. The coefficient of long run demand elasticity is equals to 1.8 ; therefore, in the long run, demand is elastic. Elasticity of supply in the long run is equals to 2.43 and supply in the long run remains elastic. Estimation of the results is reported in Table 2.

Also, the results of the demand model indicate that income significantly affects the tourists demand in Malaysia. This result supports the economic theory that any change in consumer income tends to cause a change in demand for goods and services. In addition, our results are complemented by (Salleh et al., 2007) findings, that income is a significant determinant for tourism demand in Malaysia. The coefficient of income in the demand equation is 0.16 , which means that one percent increase in real per capita income in generation countries brings a $0.16 \%$ increase in Malaysia's tourist arrival. Our results also show that income elasticity is less than unity, indicating that tourism is not a category of luxury goods in Malaysia. In other words, we can say that Malaysia is a cheap destination for tourists, as also found by Salleh et al (2007). The coefficient of exchange rate is not significant and is very small (0.05). This result indicates the appreciation of exchange rate in Malaysia has less effect on Malaysian tourism demand, although we know that the exchange rate was fixed from 2002 to 2006.We used two dummy variables as economic crises the Asian economic crisis (1997-1998) and also the 2003 SARS crisis. The results show that they had negative effect on the Malaysian tourism flow, despite these crises; tourist arrival flow to Malaysia was increased, especially from western countries (Salleh et al., 2007).

Table 2 presents the results of estimation of Eq. 1 . The equation is estimated by method of WTSLS. The dependent variable is total hotel rooms sold (LQ) as a proxy of tourist demand and also, the explanatory variables are Malaysian real exchange rate (LE), GDP per capita of sending countries and average room rate (LP) as proxy of price.

Table 1: Short run and long run price elasticity's

\begin{tabular}{lll}
\hline & Short run & Long run \\
Variables & Elasticity & Elasticity \\
\hline Price (Demand) & 0.22 & 1.83 \\
Price (Supply) & 2.43 & 5.30 \\
\hline
\end{tabular}




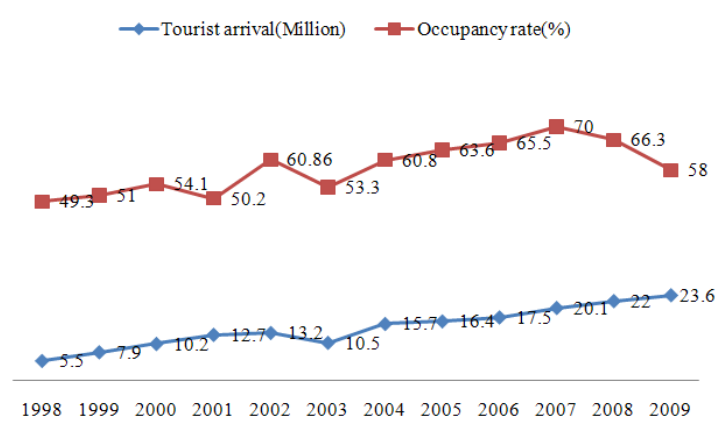

Fig. 1: Tourist arrivals and occupancy rate

Table 2: Result of the W2SLS estimation supply equation

\begin{tabular}{llllr}
\hline Variables & Coefficient & $\begin{array}{l}\text { Standard } \\
\text { error }\end{array}$ & $\begin{array}{l}\text { T- } \\
\text { statistics }\end{array}$ & Probability \\
\hline C & -9.55 & 3.460 & -2.75 & 0.007 \\
LCP & 1.47 & 0.590 & 2.48 & 0.014 \\
LQ & 0.40 & 0.140 & 2.74 & 0.007 \\
LOCCUP & 0.07 & 0.040 & 1.77 & 0.079 \\
LARR(-1) & 0.54 & 0.180 & 2.93 & 0.004 \\
DUM03 & -0.01 & 0.010 & -3.41 & 0.001 \\
R $^{2}$ cn & & 0.991 & & \\
D W & & 2.090 & & \\
\hline
\end{tabular}

Note: Dependent variable: LARR=Average room rate

Table 3: Result of the W2SLS estimation demand equation

\begin{tabular}{llllr}
\hline Variables & Coefficient & Standard & $\begin{array}{l}\text { T- } \\
\text { error }\end{array}$ & $\begin{array}{l}\text { Probability } \\
\text { statistics }\end{array}$ \\
\hline C & 1.23 & 0.35 & 3.51 & 0.000 \\
LY & 0.16 & 0.07 & 2.16 & 0.033 \\
LEX & 0.05 & 0.05 & 1.11 & 0.271 \\
LARR & -0.22 & 0.10 & -2.08 & 0.040 \\
LQ(-1) & 0.88 & 0.05 & 16.01 & 0.000 \\
DUM97 & -0.04 & 0.02 & -2.09 & 0.039 \\
DUM03 & -0.07 & 0.03 & -2.16 & 0.032 \\
R $^{2}$ cn & 0.99 & & & \\
D W & 2.08 & & & \\
\hline Note: & &
\end{tabular}

Note: Dependent variable: $\mathrm{Q}=$ Quantity room sold

Table 3 presents the results of estimation of Eq. 2 . The equation is estimated by method of W2SLS. The dependent variable is Malaysian hotels Average Room Rate (LARR) and also, the explanatory variables are consumer price index (LCP), Quantity of Rooms Sold (LQ) and hotel room occupancy rate (LOC).

The regression coefficients can be interpreted as follows: we used producer price index as a proxy of production cost but this variable was not significant and we used consumer price index instead of this variable because of the very high correlation.

Hence, the coefficient of price index in supply equation was significant with a positive sign following a unit proportional change in price index with everything else constant bringing a $1.47 \%$ positive change in average room rate. We use this variable to capture the effect of production cost on tourism price. The high coefficient of this variable indicates that the equilibrium price in the model is strongly influenced by inflation due to cost pressure.

Another variable that is included in the model is lagged of endogenous variable (LARR (-1)). According to economic theory, the price of current year is affected by previous year's price. The coefficient of lagged of endogenous variable is 0.54 and indicates the last price as the affected factor on hotel room price. We used the average occupancy rate variable in the supply equation, which measures as the related demand on supply to represent the impact of short-run disequilibrium in the Malaysian tourism market price. The coefficient of average occupancy rate is 0.07 . This result indicates that $1.0 \%$ increase in occupancy rate due to increase in demand of room in short run has a positive effect of about $0.07 \%$ on average room rate. In other words, a $1.0 \%$ increase in the room occupancy rate corresponds to a higher price of about 0.07 Malaysian currencies (RM). The average hotel occupancy rate during the sample period was 57.064. Statistics show that from year 2004, the occupancy rate had positive growth until 2007. However, despite the high growth rate of tourist arrivals the occupancy rate was $43 \%$ for 1995 and only increased to 58\% in 2009 (Fig. 1). The main reason for this case was the commensurate growth in capacity in the lodging market.

The coefficient of quantity in price equation is 0.40 and the supply elasticity equals to Eq. 3:

es $=\frac{1}{\alpha_{1}}$

Where, $\alpha$ is the coefficient of quantity

The elasticity of supply is 2.43 ; therefore in this market, supply is elastic. Also, these results are supported by Fujii and Mak (1980), in the Hawaii tourism model. According to the authors, the estimated elasticity for supply of hotel room is close to 2 .

\section{DISCUSSION}

One of the main results of being supply elastic is that in the Malaysian hotel market, there is excess supply. The statistics show that the hotel occupancy rate had a maximum around 70\% during the 1995-2009 periods. Also, the supplier can adjust the number of service workers. Therefore, they are able to adjust number of workers in the short run bases on Malaysian labour law to keep a certain offer price. 


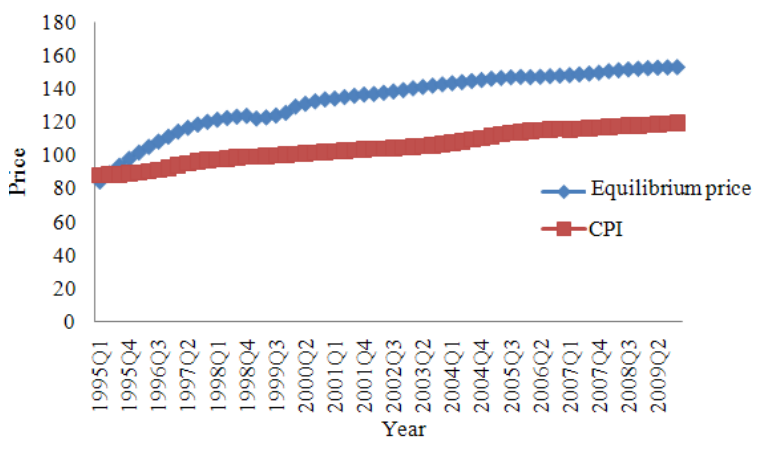

Fig. 2: Equilibrium price and consumer price index

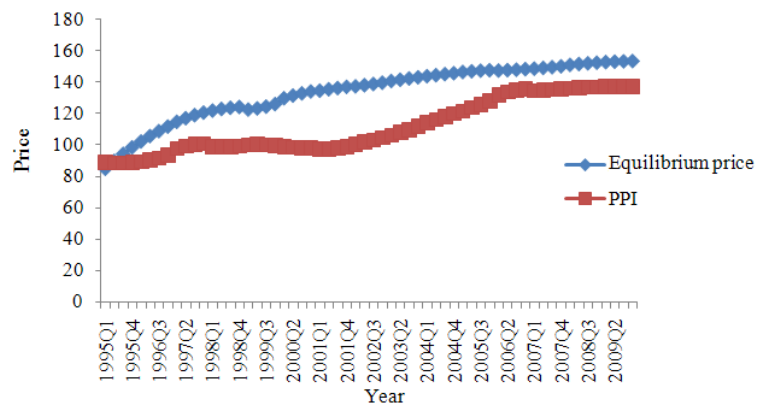

Fig. 3: Equilibrium price and producer price index

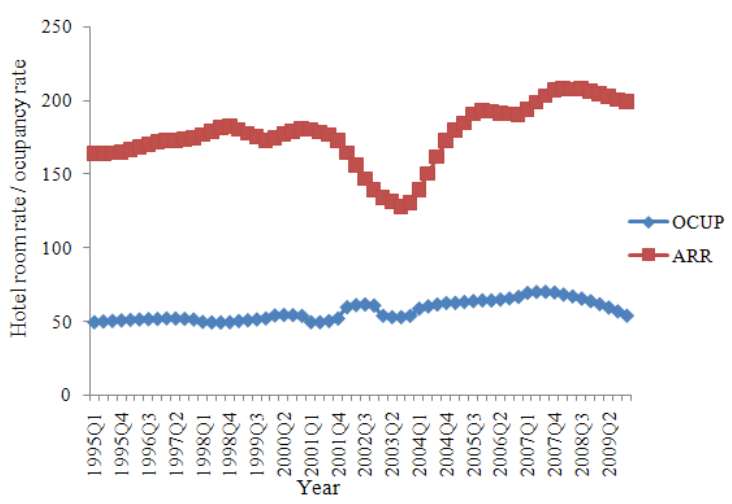

Fig. 4: Average hotel room rate and occupancy rate

Table 4: Results of estimation of Eq. 4

\begin{tabular}{lccl}
\hline Variable & Coefficient & T- statistics & Probability \\
\hline $\mathrm{C}$ & -0.02 & -2.25 & 0.02 \\
DLCP & 3.20 & 3.31 & 0.00 \\
DLOC & 0.11 & 1.18 & 0.24 \\
$\mathrm{R}^{2}=0.18$ & & & \\
\hline
\end{tabular}

These conditions can make supply elastic. Basically for our system model does not involve all factors that affect demand and supply of tourism. Therefore, we included into our model the AR term to eliminate the residual autocorrelations. The meaningful and high coefficient of AR terms represents the fact that excluding factors can explain about $40 \%$ of changes of dependent variable (This is bases on the initial estimating results of the model).

Based on the values of price in the equilibrium calculated after the estimation of the model, we can compare the consumer price index and equilibrium prices.

During the period of 1995 until 2000, the growth rate of the equilibrium price was greater than consumer price index (Fig. 2) and producer price index (Fig. 3), which means that, in the Malaysian tourism market, new infrastructure during this period had not been developed to keep pace with tourist arrivals.

In other words, the supply capacity of growth was not on par with the demand growth. But after year 2002, while analyzing the relationship between the hotel occupancy rate and the equilibrium tourism price, we noticed that exceeding demand was not able to explain the changes in tourism price. The obtained results indicate that the $1.0 \%$ change in Malaysian price index brings more than $1.0 \%(1.47 \%)$ increase in the tourism equilibrium price. This result shows that the cost inflation has considerable effect on the tourism price. On the other hand, the hotel occupancy rate during the years from 2000-2009 was almost stable (Fig. 4).

Our results indicate that $1.0 \%$ increase in the hotel occupancy rate brings $0.07 \%$ increase in the tourism equilibrium price. Perhaps this is because after the year 2000, along with the growth in hotel occupancy rates (due to an increase in tourist arrivals), the tourism industry's capacity also increased.

Based on the outcome we cannot say that the growth of the tourism price is because of the excess demand. Furthermore, the OLS method had been used to estimate the relationship between hotel room price (LARR) and Malaysian price index (LCP) as well as hotel occupancy rate (LOC) Eq. 4:

$\mathrm{DLARR}=\mathrm{C}+\alpha_{1} \mathrm{DLOC}+\alpha_{2} \mathrm{DLCP}+\mathrm{e}$

where, LARR as independent variable, LCP and LOC as explanatory variables. The results show that the coefficient of DLOC and DLCP are 0.11 and 3.2 respectively. Based on the results, an inflation pressure due to production cost is considerable on tourism price (Table 4 and Fig. 4)

During the period of 1995-2000, the growth rate of equilibrium price was greater than the consumer price index (Fig. 2) and producer price index (Fig. 3), which means that, the Malaysian tourism market infrastructure during this period was not developed in tandem with the increase in tourist arrivals. 
In other words, the supply capacity growth did not match demand growth. But after 2002, the relation between hotel occupancy rate and equilibrium tourism price was analyzed although it was not possible to the changes in tourism price.Our results indicate that $1.0 \%$ increase in the hotel occupancy rate brings $0.07 \%$ increase in tourism equilibrium price. Perhaps this is because after 2000, along with increase in hotel occupancy rate (due to increase in tourist arrivals), the tourism industry capacity also increased. Based on the outcome we cannot say the growth of the tourism price is because of the excess demand. The obtained results indicate that the $1.0 \%$ change in Malaysian price index brings more than $1.0 \%(1.47 \%)$ increase in the tourism equilibrium price.

\section{CONCLUSION}

During the period of 1995-2000, the growth rate of equilibrium price was greater than the consumer price index and producer price index, which means that, the Malaysian tourism market infrastructure during this period was not developed in tandem with the increase in tourist arrivals. In other words, the supply capacity growth did not match demand growth. But after 2002, the relation between hotel occupancy rate and equilibrium tourism price was analyzed although it was not possible to the changes in tourism price. Our results indicate that $1.0 \%$ increase in the hotel occupancy rate brings $0.07 \%$ increase in tourism equilibrium price. Perhaps this is because after 2000, along with increase in hotel occupancy rate (due to increase in tourist arrivals), the tourism industry capacity also increased. Based on the outcome we cannot say the growth of the tourism price is because of the excess demand. This result shows that the cost inflation has considerable effect on the tourism price. On the other hand, the hotel occupancy rate during the years from 2000-2009 was almost stable.

\section{REFERENCES}

Anastassiou, T. and C. Dritsaki, 2005. Tax revenues and economic growth: An empirical investigation for Greece using causality analysis. J. Soc. Sci., 1: 99-104. DOI: 10.3844/jssp.2005.99.104
Arbel, A. and S.A. Ravid, 1983. An industry energy price impact model: The case of the hotel industry. Applied Econ., 15: 705-714. DOI: 10.1080/00036848300000060

Bird, R.M., 1992. Taxing tourism in developing countries. World Dev., 20: 1145-1158. DOI: 10.1016/0305-750X(92)90006-H

Bonham, C.S. and B. Gangnes, 1996. Intervention analysis with cointegrated time series: The case of the Hawaii hotel room tax. Applied Econ., 28: 1281-1293. DOI: 10.1080/000368496327831

Crouch, G.I., 1994. The study of international tourism demand: A survey of practice. J. Travel Res., 32: 41-55. DOI: 10.1177/004728759403200408

Fujii, E.T. and J. Mak, 1980. Forecasting tourism demand; Some methodological issues. Annal. Regional Sci., 15: 72-82. DOI: 10.1007/BF01287440

Mohebi, M., K.A. Rahim, L. Chin and K.W. Awang, 2011. Tax exportability in tourism market. Am. J. Econ. Bus. Admin., 3: 410-415. DOI: 10.3844/ajebasp.2011.410.415

Salleh, N.H.M., R. Othman and S. Ramachandran, 2007. Malaysia's tourism demand from selected countries: The ARDL approach to cointegration. Int. J. Econ. Manage., 1: 345-363. Qu, H., P. Xu and A. Tan, 2002. A simultaneous equations model of the hotel room supply and demand in Hong Kong. Int. J. Hospitality Manage., 21: 455-462. DOI: 10.1016/S0278-4319(02)00031-2

Seifolddini-Faranak, M.S. Fard and H. Ali, 2009. Distribution and determining of tourist attractions and modeling of tourist cities for the city of Isfahan-Iran. Am. J. Econ. Bus. Admin., 1: 160166. DOI: 10.3844/ajebasp.2009.160.166

Smith, S.L.J., 1988. Defining tourism a supply-side view. Annal. Tourism Res., 15: 179-190. DOI: 10.1016/0160-7383(88)90081-3

Zhou, T., C. Bonham and B. Gangnes, 2007. Modeling the supply and demand for tourism: A fully identified VECM approach. University of Hawaii at Manoa. 